\title{
Exposure to thoracic dust, airway symptoms and lung function in cement production workers
}

\author{
K-C. Nordby*, A.K.M. Fell ${ }^{\#,}$, H. Notø*, W. Eduard*, M. Skogstad*, \\ Y. Thomassen*, A. Bergamaschi ${ }^{+}$, J. Kongerud ${ }^{\#, \S}$ and H. Kjuus*
}

ABSTRACT: Cement dust exposure has previously been associated with airway symptoms and ventilatory impairment. The aim of the present study was to examine lung function and airway symptoms among employees in different jobs and at different levels of exposure to thoracic dust in the cement production industry.

At the start of a 4-yr prospective cohort study in 2007, exposure to cement dust, symptoms and lung function were recorded cross-sectionally in 4,265 employees in 24 European cement plants. Bronchial exposure was assessed by 2,670 full-shift dust samples with cyclones collecting the thoracic aerosol fraction. A job exposure matrix was constructed by grouping dust concentrations according to job type and plant.

Elevated odds ratios for symptoms and airflow limitation (range 1.2-2.6 in the highest quartile), but not for chronic bronchitis, were found in the higher quartiles of exposure compared with the lowest quartile. Forced expiratory volume in $1 \mathrm{~s}$ (FEV1) showed an exposure-response relationship with a 270-mL deficit of FEV $1(95 \% \mathrm{Cl} \mathrm{190-300} \mathrm{mL)} \mathrm{in} \mathrm{the} \mathrm{highest} \mathrm{compared} \mathrm{with} \mathrm{the} \mathrm{lowest}$ exposure level.

The results support the hypothesis that exposure to dust in cement production may lead to respiratory symptoms and airway obstruction.

KEYWORDS: Airflow limitation, airway obstruction, cross-sectional studies, epidemiology, occupational exposure

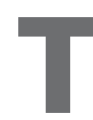
he cement industry provides building material for land-based and off-shore installations. Cement is typically produced by heating a homogenous blend of limestone and clay, which is then adjusted to a suitable content of calcium, silicon, aluminium and iron in a kiln. During its heating to $1,450^{\circ} \mathrm{C}$, clinker is formed, which contains calcium silicates, calcium aluminates and calcium ferrites. Clinker is subsequently ground with gypsum and other additives, resulting in a fine particulate powder called cement. In contact with water, clinker partly dissolves and forms an aqueous slurry of high alkalinity, giving clinker and cement strong irritant properties [1]. Cement production workers are exposed to airborne particles of raw materials, clinker, additives and to the final cement product, and their work has been linked to changes in lung function and airway symptoms [2].

Early studies on adverse respiratory effects of cement dust exposure include both non-positive studies and studies connecting cement production work with chronic airway inflammation and reduction of dynamic lung volumes $[3,4]$. Other studies indicate a reduced forced vital capacity (FVC) or forced expiratory volume in $1 \mathrm{~s}$ (FEV1) [5-9] and a higher prevalence of chronic respiratory symptoms [7-10] and chronic obstructive pulmonary disease (COPD) [11] in cement production workers.

Several studies of lung function in cement production workers were non-positive [10, 12-14]. Thus, the literature is conflicting and conclusions about exposure-response relationships or safe levels of exposure cannot be drawn [2].

To further investigate exposure-response relationships between cement dust exposure and respiratory effects, The European Cement Association (CEMBUREAU) has initiated a large, multi-national, 4 -yr prospective study monitoring exposure and lung function in cement workers in 24 plants in eight countries. The cohort was established in 2007, with scheduled follow-up in 2009 and 2011, including spirometry tests and full-shift personal exposure
AFFILIATIONS

*National Institute of Occupational Health $(\mathrm{NIOH})$

\# Institute of Clinical Medicine, Faculty of Medicine, University of Oslo,

${ }^{\S}$ Dept of Respiratory Medicine, Rikshospitalet, Oslo University Hospital, Oslo,

"Dept of Occupational and Environmental Medicine, Telemark Hospital, Skien, Norway. +University of Rome Tor Vergata, and Catholic University of the Sacred Heart, Rome, Italy.

CORRESPONDENCE

K-C. Nordby

National Institute of Occupational Health

P.0. Box 8149 Dep

NO-0033 Oslo

Norway

E-mail: kcn@stami.no

Received:

Jan 162011

Accepted after revision: April 242011

First published online: June 092011 
measurements of the thoracic aerosol fraction in selected workers. Inhaled particles can penetrate and deposit in different parts of the human respiratory system, from the nose and mouth, to the bronchi and alveoli of the lung. Particles with a mass median aerodynamic particle size of $10 \mu \mathrm{m}$ and geometric standard deviation of 1.5 are defined as the thoracic aerosol fraction and may penetrate into the lung [15]. The thoracic fraction was chosen because it was considered to be the most relevant health-related aerosol fraction with regards to bronchial exposure. This fraction estimates the particles that deposit in the bronchi, the site of hypothesised obstructive lung changes, better than inhalable dust, total dust or respirable dust [16]. The aims of the present study were to describe the cohort and present the initial cross-sectional analysis of lung function and airway symptoms and associations with exposure to thoracic dust in the cement production industry.

\section{METHODS}

\section{Study population}

Initially, all cement plants who were members of CEMBUREAU were candidates for participation in the study. We intended to include plants representing different geographical regions and exposure levels. 25 plants agreed to participate in the study, but for practical reasons, one plant in Turkey was excluded. The inclusion criteria at the plant level were: 1) completeness of personal records; 2) the possibility to perform spirometry tests on all employees as well as quantitative exposure measurements; and 3) no previous production of asbestos cement. Workers employed in the quarries were excluded to reduce distortion of the results by possible exposure to lung-reactive gases and dust other than cement dust. Furthermore, employees in out-sourced services were excluded to prevent problems with the tracking of individuals. 24 plants in eight countries were included, contributing 4,265 employees to the cross-sectional examinations performed in 2007 (table 1). Permissions from ethical research committees (REK Sør-øst, Oslo, Norway and Swedish committee for ethics, Stockholm, Sweden) were obtained. All participants signed a written consent form after receiving oral and written information about the study.

The questionnaires used in the study were translated into all nine languages spoken in the participating plants and the translations were checked by independent translators using the English version as the standard.

\section{Spirometry and symptoms}

Vitalograph 2160 spirometers (Vitalograph, Buckingham, UK) were made available to each plant. Spirometry was carried out by the occupational health service staff at each plant or by

TABLE 1 Study population characteristics of cement production plant employees in a multi-national cross-sectional study

\begin{tabular}{|c|c|c|c|c|c|c|c|c|c|}
\hline & Total & Estonia & Greece & Italy & Norway & Spain & Sweden & Switzerland & Turkey \\
\hline Plants & 24 & 1 & 1 & 5 & 2 & 2 & 3 & 1 & 9 \\
\hline Employees & 4265 & 112 & 100 & 541 & 249 & 330 & 331 & 93 & 2509 \\
\hline Total employees per country \% & 100 & 2.6 & 2.3 & 12.7 & 5.8 & 7.7 & 7.8 & 2.2 & 58.8 \\
\hline Age yrs & $39.9 \pm 10$ & $44.0 \pm 10$ & $37.2 \pm 8.9$ & $43.3 \pm 9.9$ & $44.7 \pm 12$ & $46.2 \pm 11$ & $46.9 \pm 11$ & $46.3 \pm 9.6$ & $36.7 \pm 7.9$ \\
\hline Males $^{\#}$ & $4002(94)$ & $50(45)$ & $92(92)$ & $536(99)$ & $211(85)$ & $318(96)$ & $303(92)$ & $91(98)$ & $2401(96)$ \\
\hline Asthma & $116(2.7)$ & $6(5.4)$ & $3(3.0)$ & $24(4.4)$ & $19(7.6)$ & $17(5.2)$ & $16(4.8)$ & $5(5.4)$ & $26(1.0)$ \\
\hline \multicolumn{10}{|l|}{ Smoking information } \\
\hline Never-smoker ${ }^{\S}$ & 2055 (48) & $41(37)$ & $38(38)$ & $331(61)$ & $112(45)$ & $156(47)$ & $195(59)$ & $35(38)$ & $1147(46)$ \\
\hline Former smoker & $353(8.3)$ & $8(7.1)$ & $8(8.0)$ & $32(5.9)$ & $53(21)$ & $56(17)$ & $74(22)$ & $21(23)$ & $101(4.0)$ \\
\hline Smoker, unspecified & $113(2.6)$ & $4(3.6)$ & $3(3.0)$ & $4(0.7)$ & $5(2.0)$ & $10(3.0)$ & $6(1.8)$ & $3(3.2)$ & $78(3.1)$ \\
\hline \multicolumn{10}{|l|}{ Current smoker } \\
\hline $1-9$ cigarettes $\cdot$ day $^{-1}$ & $300(7.0)$ & $15(13)$ & $5(5.0)$ & $31(5.7)$ & $24(9.6)$ & $33(10)$ & $12(3.6)$ & $2(2.2)$ & $178(7.1)$ \\
\hline Administration & $629(15)$ & $15(13)$ & $20(20)$ & $48(8.9)$ & $34(14)$ & $41(12)$ & $40(12)$ & $14(15)$ & 417 (17) \\
\hline Production & $1406(33)$ & $48(43)$ & $34(34)$ & $142(26)$ & $73(29)$ & $132(40)$ & $109(33)$ & $28(30)$ & $840(34)$ \\
\hline Cleaning & $80(1.9)$ & $16(14)$ & $1(1.0)$ & $43(7.9)$ & $4(1.6)$ & $5(1.5)$ & $5(1.5)$ & $1(1.1)$ & $5(0.2)$ \\
\hline Maintenance & $1132(27)$ & $1(0.9)$ & $27(27)$ & $147(27)$ & $62(25)$ & $79(24)$ & 93(28) & $28(30)$ & $695(28)$ \\
\hline Foreman & $66(1.5)$ & $5(4.5)$ & $1(1.0)$ & $7(1.3)$ & $3(1.2)$ & $11(3.3)$ & $6(1.8)$ & $0(0.0)$ & $33(1.3)$ \\
\hline Laboratory & 235 (5.5) & $3(2.7)$ & $6(6.0)$ & $47(8.7)$ & $16(6.4)$ & $10(3.0)$ & $9(2.7)$ & $4(4.3)$ & $140(5.6)$ \\
\hline Other & $543(13)$ & $12(11)$ & $11(11)$ & $95(18)$ & $9(3.6)$ & $43(13)$ & $26(7.9)$ & $2(2.2)$ & $345(14)$ \\
\hline Several job types & $174(4.1)$ & $12(11)$ & $0(0.0)$ & $12(2.2)$ & $48(19)$ & $9(2.7)$ & $43(13)$ & $16(17)$ & $34(1.4)$ \\
\hline Previous exposuref & $1643(39)$ & $64(57)$ & $48(48)$ & $247(46)$ & $129(52)$ & $154(47)$ & $239(72)$ & $42(45)$ & $720(29)$ \\
\hline
\end{tabular}

Data are presented as $n$, mean \pm SD or $n(\%)$, unless otherwise stated. ${ }^{*}$ : percentages are calculated by country; " : self-report of doctor-diagnosed asthma; ${ }^{+}$: self-report of allergy; ${ }^{\text {s: }}$ : never-smoker category includes those having smoked for $<1 \mathrm{yr}$; some of whom reported a life-time dose $>0$ pack-yrs; ${ }^{f}$ : previous occupational exposure to dust or gases. 
research staff familiar with the local conditions. All technicians participated in training sessions and received written manuals and instruction videos to standardise procedures. Site visits were performed to secure compliance with the study protocol.

Spirometry was performed according to the American Thoracic Society (ATS)/European Respiratory Society (ERS) guidelines [17]. Reversibility testing was not considered feasible and thus not performed. For repeatability and end-of-test (EOT) criteria, a 150-mL difference between the best and second best test of FVC and FEV1 and 100-mL increase of volume during the last $2 \mathrm{~s}$ of the FVC manoeuvre were chosen, respectively. A valid FVC measurement should meet both the repeatability and EOT criteria. We calculated the FEV1/FVC and the percentage of the predicted values for FVC (FVC \% predicted) and FEV1 (FEV1\% predicted) using published reference values for Europeans [18]. Airflow limitation was determined according to two alternative definitions, using FEV1/FVC $<0.7$ as a common definition of COPD or FEV1/FVC $<$ lower limit of the normal (LLN) calculated for age and sex [18].

Characteristics of the study population stratified by country are presented in table 1 . Information on airway symptoms was collected on the day of the spirometry tests from all participants, using the International Union Against Tuberculosis and Lung Disease (IUATLD) questionnaire [19] with additional questions about respiratory and cardiovascular disease, allergy, asthma and smoking.

\section{Exposure questionnaires and exposure assessment}

In connection with spirometry, all participants filled out a questionnaire on personal historical occupational exposure developed by the National Institute of Occupational Health (NIOH, Oslo, Norway) and the National Coordinators of the study. Another questionnaire describing job types and work conditions on the day of exposure sampling was completed after each full-shift sampling by those employees selected to participate in exposure sampling. The same questions and categories were used as in the historical exposure questionnaire, with added information about the sampling (time, flow and equipment). Workers were selected for exposure measurements once or several times using a group-based strategy, but those who did not enter the cement production areas as part of their daily work were not selected for sampling. Personal full-shift samples of the thoracic aerosol fraction were collected using GK 2.69 thoracic cyclones (BGI Instruments, Waltham, MA, USA) in compliance with the thoracic sampling convention at a flow rate of $1.6 \mathrm{~L} \cdot \mathrm{min}^{-1}$ [16]. Dust was collected on $37 \mathrm{~mm}$ diameter PVC filters with pore size $5 \mu \mathrm{m}$ (Millipore, Billerica, MA, USA; SKC Inc., Washington, PA, USA; and PALL Corp, Ann Arbor, MI, USA). Personal sampling pumps were adjusted to $1.6 \mathrm{~L} \cdot \mathrm{min}^{-1}$ before sampling. The airflow at the end of sampling was accepted if it was between 1.28 and $1.92 \mathrm{~L} \cdot \mathrm{min}^{-1}$, otherwise the measurement was considered not valid. The dust mass on the filters was determined by gravimetry according to a standard procedure using a Sartorius MC5 Micro Balance (Sartorius AG, Goettingen, Germany). The use of personal respiratory protection was reported in the questionnaire.

\section{Statistical analysis}

The exposure measurements were grouped by plant and job type in a job exposure matrix (JEM), where a group median exposure was calculated for each job type and plant combination. Job type categories used in the JEM were administration, production, cleaning, maintenance, foreman, laboratory and other, and an eighth category of workers reporting tasks in several job types. An exposure value was allocated to each employee based on the median value calculated in the JEM, which was independent of individual measurement values or non-participation in the exposure sampling. Associations between exposure and airway symptoms, airflow limitation and lung function were investigated using exposure estimated by two alternative strategies: 1 ) job types using the administration as reference and 2) exposure estimated using the JEM. As estimates obtained for administration personnel entering production areas were not representative of the majority of the administration employees not doing so, the administration was excluded from analyses that were based on the JEM. The JEM exposure value was either used in models assuming a linear relationship with outcomes, or categorised in quartiles and used as dummy variables in models not assuming linear relationships.

Lung function was analysed using the observed values of FEV1, FVC and FEV1/FVC in models adjusted for sex, age, standing height and smoking by multiple regression. Participants reporting doctor-diagnosed asthma were excluded from the main analysis.

Data input was performed in Access 2003 (Microsoft Corp., Redmond, WA, USA). SPSS 18.0 (SPSS Inc., Chicago, IL, USA) was used for descriptive statistics, logistic and linear regression analysis. Potential confounders were assessed and adjusted for if they altered the effect estimates of associations by $\geqslant 15 \%$.

\section{RESULTS}

\section{Spirometry and symptoms}

A total of 4,265 participants completed questionnaires and performed spirometry tests. The prevalence of symptoms was higher in the production, maintenance, other and several job type groups compared with administration and in those reporting previous occupational exposure to dust or gases compared with no previous exposure (table 2). We obtained 3,332 (78\%), $3,966(93 \%)$ and 3,206 (75\%) valid tests regarding FVC, FEV1 and FEV1/FVC, respectively. Reduced dynamic lung volumes were found in most exposed groups compared with administration (table 3).

FEV1 was more affected than FVC. Lung function did not seem to be influenced by previous occupational exposure to dust and gases (table 3). Smoking was associated with increased symptom prevalence and reduced dynamic lung volumes (data not shown). FEV1/FVC decreased with age and the prevalence of airflow limitation increased with age, using either FEV1/FVC $<0.7$ or FEV1/FVC $<$ LLN (data not shown). Differences in asthma, allergy and smoking habits between countries were found (table 1).

\section{Exposure}

The geometric mean of 2,670 exposure samples was $0.85 \mathrm{mg} \cdot \mathrm{m}^{-3}$ (geometric standard deviation 4.6). The group median values of thoracic dust levels in the JEM ranged from 0.07 to $36 \mathrm{mg} \cdot \mathrm{m}^{-3}$. Using weighting by number of employees in each job type by plant group, exposure medians were divided into quartiles, resulting in delimiting values of $0.49,1.08$ and $1.73 \mathrm{mg} \cdot \mathrm{m}^{-3}$ 
TABLE 2 Prevalence of self-reported symptoms during the last 12 months in categories of job type and previous occupational exposure in cement production plant employees

\begin{tabular}{|c|c|c|c|c|c|}
\hline & Subjects $n$ & Coughing & $\begin{array}{l}\text { Wheezing and } \\
\text { dyspnoea }\end{array}$ & $\begin{array}{c}\text { Coughing, wheezing and } \\
\text { dyspnoea }\end{array}$ & $\begin{array}{c}\text { Chronic } \\
\text { bronchitis }\end{array}$ \\
\hline \multicolumn{6}{|l|}{ Job type } \\
\hline Administration & 629 & $100(16)$ & $23(3.7)$ & $11(1.7)$ & $9(1.4)$ \\
\hline Production & 1406 & $286(20)$ & $87(6.2)$ & $64(4.6)$ & $57(4.1)$ \\
\hline Cleaning & 80 & 15 (19) & $2(2.5)$ & $1(1.3)$ & $3(3.8)$ \\
\hline Laboratory & 235 & $51(22)$ & $15(6.4)$ & $11(4.7)$ & $8(3.4)$ \\
\hline Other/unknown & 543 & $107(20)$ & $29(5.3)$ & $19(3.5)$ & $13(2.4)$ \\
\hline Several job types & 174 & $45(26)$ & $22(13)$ & $15(8.6)$ & $8(4.6)$ \\
\hline \multicolumn{6}{|l|}{ Previous exposure $\#$} \\
\hline No & 2622 & $493(19)$ & $135(5.1)$ & $85(3.2)$ & $71(2.7)$ \\
\hline Yes & 1643 & $380(23)$ & $117(7.1)$ & $81(4.9)$ & $68(4.1)$ \\
\hline
\end{tabular}

Data are presented as $n(\%)$, unless otherwise stated. ${ }^{\#}$ : previous occupational exposure to dust or gases.

between the quartiles. One JEM group of 37 employees with a level of $36 \mathrm{mg} \cdot \mathrm{m}^{-3}$ was excluded as outliers from the JEM. The exposure levels by job type category are shown in figure $1.95 \%$ gave information on their use of personal respiratory protection. No use, occasional use and use most of the time were reported by 18,39 and $43 \%$ of employees, respectively. The use of personal respiratory protection was more prevalent most of the time in the highest quartile of median exposure, $(65 \%)$, declining to $54 \%$ in the second highest quartile, $31 \%$ in the second lowest and finally, $35 \%$ in the lowest quartile.

TABLE 3 Lung function among cement production plant employees stratified on selected exposure variables and covariates

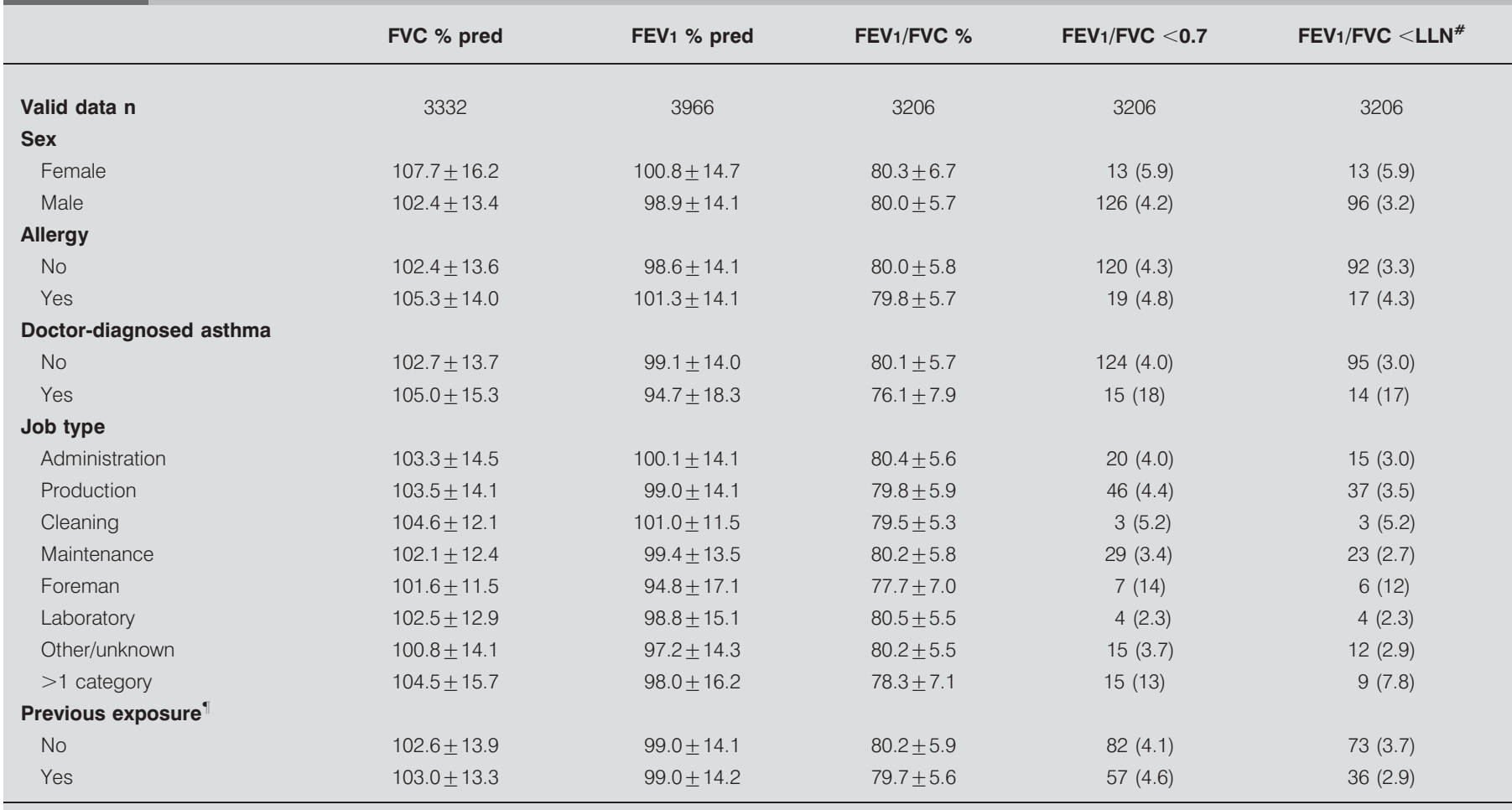

Data are presented as mean \pm SD or $n(\%)$, unless otherwise stated. FVC: forced vital capacity; \% pred: \% predicted; FEV1: forced expiratory volume in $1 \mathrm{~s} .{ }^{\#}$ : Iower limit of the normal (LLN) using the European Community for Coal and Steel/European Respiratory Society prediction equations for predicted values minus 1.64 mean squared deviation about the regression line $(\sim 5$ th percentile); $"$ : previous occupational exposure to dust and gases. 


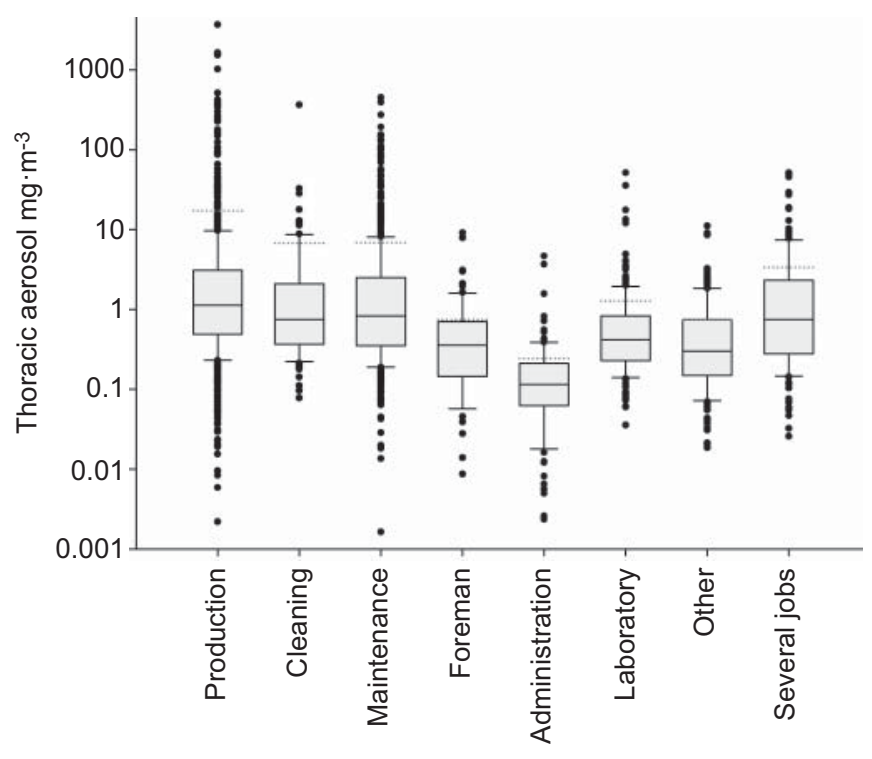

FIGURE 1. Thoracic fraction of dust measured by personal sampling according to job type. The median (central line in boxes), 25th-75th percentiles (boxes), 10th and 90th percentiles (whiskers) and extreme values (dots beyond the whiskers) by job type are shown. All plants were included ( $n=2,670$ samples). Dotted lines represent the arithmetic means of exposure. The employees belonging to the administration job type and also participating in the sampling programme consist of employees working in administration, but serving tasks such as supervision in the production areas.

\section{Associations between exposure and outcomes}

The adjusted odds ratios (ORs) of symptom prevalence were higher in the production, maintenance, foreman, laboratory and several job type categories compared with administration, while airflow limitation was not associated with job type except among the foremen (table 4). Exposure from the JEM was associated with symptom prevalence (table 5) using the quartiles and the linear value of group median exposure. Reduced dynamic lung volumes were found in the productionrelated departments compared with administration (table 6). Exposure from the JEM was associated with reduced dynamic lung volumes using the quartiles and the nominal value from the JEM, showing a definite exposure-response relationship for FEV1 (table 7).

Previous occupational exposure to dust and gases was associated with symptoms (table 4), but not with lung function (table 6). Among those with doctor-diagnosed asthma who were excluded from the primary analysis, both symptoms and reduced dynamic lung volumes were likewise associated with job type, but the associations were weaker (results not shown).

The set of dummy variables for plant confounded the effect estimates of cleaning on symptoms, of foreman on chronic bronchitis and of several job types on airflow limitation. For the lung volume analyses, adjustment for plant was necessary for all strata and job types. The coefficients for the set of dummy variables were highly significant both in models of symptoms and lung function, indicating that there are differences in the effect of job type according to plant (data not shown). In table 7 the associations are presented allowing for the use of personal respiratory protection, as the associations of FVC were confounded, but those of FEV1 and FEV1/FVC were not.

We analysed the influence of separate countries and age strata on the associations. Associations between exposure and lung function and symptoms were stronger among the non-Turkish participants, however, chronic bronchitis showed stronger associations among the Turkish participants. Associations with

TABLE 4 Odds ratios (ORs) of airway symptoms and airflow limitation by job type in cement production plant employees ${ }^{\#}$

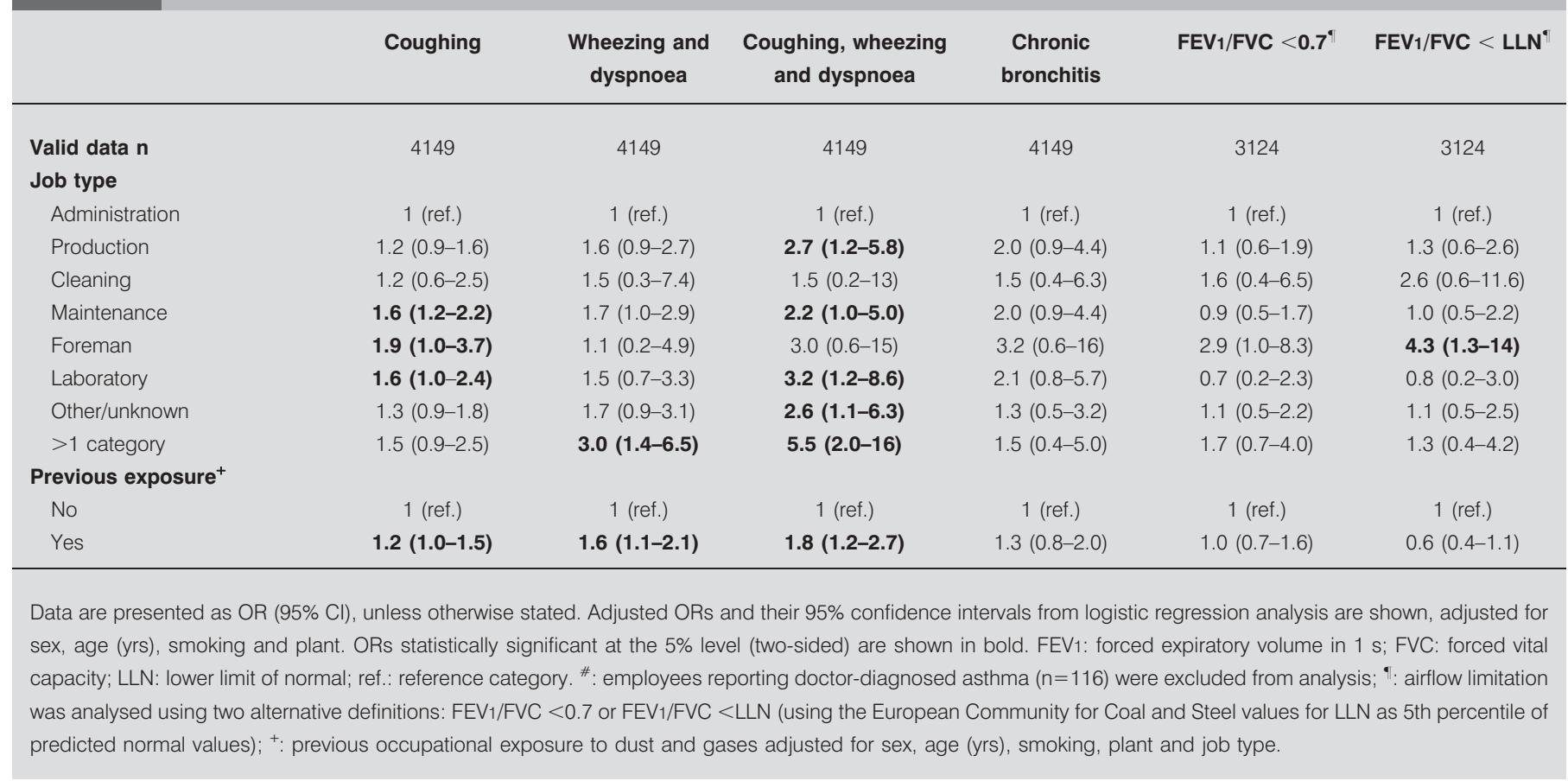


TABLE 5 Odds ratios (ORs) of airway symptoms and airflow limitation by dust exposure level in cement production plant employees $^{\#}$

\begin{tabular}{|c|c|c|c|c|c|c|}
\hline & Coughing & $\begin{array}{c}\text { Wheezing and } \\
\text { dyspnoea }\end{array}$ & $\begin{array}{l}\text { Wheezing, dyspnoea } \\
\text { and coughing }\end{array}$ & $\begin{array}{c}\text { Chronic } \\
\text { bronchitis }\end{array}$ & $\mathrm{FEV}_{1 / \mathrm{FVC}}<0.7^{\circ}$ & $\mathrm{FEV}_{1 / \mathrm{FVC}}<$ LLN $^{*}$ \\
\hline Valid data $n$ & 3495 & 3495 & 3495 & 3495 & 2599 & 2599 \\
\hline \multicolumn{7}{|c|}{$\begin{array}{l}\text { Exposure from JEM } \\
\text { (quartiles) } \mathrm{mg} \cdot \mathrm{m}^{-3}\end{array}$} \\
\hline$<0.49$ & 1 (ref.) & 1 (ref.) & 1 (ref.) & 1 (ref.) & 1 (ref.) & 1 (ref.) \\
\hline$>1.74$ & $1.2(0.9-1.6)$ & $2.6(1.6-4.4)$ & $2.3(1.3-4.4)$ & $0.5(0.2-0.8)$ & $1.9(1.0-3.5)$ & $1.8(0.9-3.8)$ \\
\hline \multicolumn{7}{|c|}{$\begin{array}{l}\text { Exposure from JEM (linear) } \\
\mathrm{mg} \cdot \mathrm{m}^{-3}\end{array}$} \\
\hline Exposure effect ${ }^{+}$ & $1.03(0.99-1.08)$ & $1.10(1.02-1.18)$ & $1.09(1.00-1.19)$ & $0.88(0.77-1.00)$ & $1.06(0.95-1.17)$ & $1.05(0.94-1.18)$ \\
\hline
\end{tabular}

Data are presented as OR $(95 \% \mathrm{Cl})$, unless otherwise stated. Adjusted ORs and their $95 \%$ confidence intervals from logistic regression analysis are shown adjusted for sex, age (yrs) and smoking. The data are a comparison between strata of exposure from the job exposure matrix (JEM) based on the median exposure allocated to each individual. ORs statistically significant at the $5 \%$ level (two-sided) are shown in bold. FEV1: forced expiratory volume in $1 \mathrm{~s}$; FVC: forced vital capacity; LLN: Iower limit of normal; ref.: reference category. ${ }^{\#:}$ employees reporting doctor-diagnosed asthma $(n=116)$ and employees in the administration $(n=629)$ were excluded from analysis; 52 employees with a median exposure $>26 \mathrm{mg} \cdot \mathrm{m}^{-3}$ were excluded as outliers, as these were likely to be unrepresentative samples; ": airflow limitation was analysed using two alternative definitions: FEV1/FVC $<0.7$ or FEV1/FVC $<$ LLN (using the European Community for Coal and Steel values for LLN as 5 th percentile of normal values); ${ }^{+}$: exposure effect in $\mathrm{mg} \cdot \mathrm{m}^{-3}$ assuming linear associations between exposure taken from the exposure matrix and outcome, adjustments were made for sex, age (yrs) and smoking.

dynamic lung volumes did not change substantially on exclusion of participants country by country. When restricted to age $<45$ yrs, associations of job types with symptoms, chronic bronchitis, and airflow limitation were stronger except for the other and several job type groups. Using JEM values for exposure among those $<45$ yrs of age, associations with symptoms were stronger, except for chronic bronchitis, which was unchanged, and airflow limitation, which showed reduced estimates of effect.

\section{DISCUSSION}

In this multi-national study, we have demonstrated that exposure to dust in cement production plants is associated with airway symptoms as well as reduced dynamic lung

TABLE 6 Lung function differences according to job type and previous occupational exposure to dust and gases in cement production plant employees ${ }^{\#}$

\begin{tabular}{|c|c|c|c|}
\hline & FVC mL & FEV1 $\mathrm{mL}$ & $\mathrm{FEV}_{1 / \mathrm{FVC}} \%$ \\
\hline Valid data $\mathbf{n}$ & 3248 & 3857 & 3124 \\
\hline Administration & 0 (ref.) & 0 (ref.) & 0 (ref.) \\
\hline Production & $-70(-140-6)$ & $-100(-160--40)$ & $-0.4(-1.0-0.2)$ \\
\hline Cleaning & $-200(-390--13)$ & $-150(-300-1)$ & $-1.1(-2.7-0.3)$ \\
\hline Laboratory & $-120(-240--7)$ & $-120(-210--25)$ & $-0.4(-1,3-0.6)$ \\
\hline Other/unknown & $-160(-250--71)$ & $-130(-210--63)$ & $-0.1(-0.8-0.7)$ \\
\hline$>1$ category & $-190(-340--45)$ & $-190(-300--85)$ & $0.2(-0.9-1.4)$ \\
\hline \multicolumn{4}{|c|}{ Previous exposure } \\
\hline No & 0 (ref.) & 0 (ref.) & 0 (ref.) \\
\hline
\end{tabular}

Data are presented as coefficient $(95 \% \mathrm{Cl}$ ), unless otherwise stated. Linear regression coefficients are interpreted as $\mathrm{mL}$ difference compared with administration (forced vital capacity (FVC) and forced expiratory volume in $1 \mathrm{~s}(\mathrm{FEV} 1)$ ) and \% points of change compared to administration (FEV $\left.1 / F V_{C}\right)$ with $95 \%$ confidence intervals. Adjustments were made for sex, age (yrs), standing height ( $\mathrm{cm}$ ), smoking and plant. Coefficients that were statistically significant at the $5 \%$ level (two-sided) are shown in bold. ref.: reference category. ${ }^{*}$ : employees reporting doctor-diagnosed asthma $(n=116)$ were excluded from analysis; ": previous occupational exposure to dust and gases were adjusted for sex, age (yrs), standing height (cm), smoking, plant and job type. 


\begin{tabular}{|c|c|c|c|}
\hline & FVC mL & FEV $1 \mathrm{~mL}$ & $\mathrm{FEV}_{1 / \text { FVC } \%}$ \\
\hline \multicolumn{4}{|c|}{ Exposure from JEM (quartiles) $\mathrm{mg} \cdot \mathrm{m}^{-3}$} \\
\hline$<0.49$ & 0 (ref.) & 0 (ref.) & 0 (ref.) \\
\hline Exposure $>1.74 \mathrm{mg} \cdot \mathrm{m}^{-3}$ & $-300(-390--220)$ & $-270(-330--200)$ & $-0.8(-1.4--0.2)$ \\
\hline \multicolumn{4}{|c|}{ Exposure from JEM (linear) ${ }^{9} \mathrm{mg} \cdot \mathrm{m}^{-3}$} \\
\hline Exposure effect & $-32(-48--16)$ & $-33(-46--21)$ & $-0.15(-0.27--0.04)$ \\
\hline
\end{tabular}

Data are presented as coefficient $(95 \% \mathrm{Cl})$, unless otherwise stated. Linear regression coefficients are interpreted as $\mathrm{mL}$ difference compared with the reference category (ref.) (forced vital capacity (FVC) and forced expiratory volume in $1 \mathrm{~s}(\mathrm{FEV} 1)$ ) and \% points of change compared to the reference category (FEV $1 / F V C)$ with $95 \%$ confidence intervals. Adjustments were made for sex, age (yrs), standing height $(\mathrm{cm})$, smoking and the use of personal respiratory protection. Coefficients that were statistically significant at the $5 \%$ level (two-sided) are shown in bold. JEM: job exposure matrix. * : employees reporting doctor-diagnosed asthma ( $\mathrm{n}=116)$ and employees in the administration ( $n=629$ ) were excluded from analysis; 37 employees with a median exposure of $>36 \mathrm{mg} \cdot \mathrm{m}^{-3}$, which was considered unrepresentative, and seven, nine and seven employees with uncertain height or age were excluded as outliers in the analysis of FVC, FEV 1 , and FEV1/FVC, respectively; ": exposure effect per $\mathrm{mg} \cdot \mathrm{m}^{-3}$, adjusted for sex, age (yrs), standing height $(\mathrm{cm})$, smoking and the use of personal respiratory protection assuming linear associations between exposure taken from the JEM and outcome.

volumes (FEV1 and FVC). This is in accordance with the study hypothesis. We utilised job types and exposure to the thoracic dust fraction, estimated by a within-study generated JEM as a measure of exposure.

\section{Exposure-outcome associations}

Exposure and airway symptoms were associated with ORs ranging between 1.2 and 2.6 in the highest quartile of exposure, comparable to a Danish study of cement production workers with a suggested median exposure level of $3 \mathrm{mg} \cdot \mathrm{m}^{-3}$ of total dust and $0.5 \mathrm{mg} \cdot \mathrm{m}^{-3}$ of respirable dust $[11,20]$. Other studies including workers exposed to $>10 \mathrm{mg} \cdot \mathrm{m}^{-3}$ of total dust demonstrated excess symptoms among the highest exposed workers [8, 21-23]. The association of exposure with chronic bronchitis in the present study was weaker than with cough and wheezing. In a study from Taiwan with a mean exposure $3.6 \mathrm{mg} \cdot \mathrm{m}^{-3}$ of respirable dust, ORs for symptoms ranged from 1.2 to 1.5 , but were close to unity for chronic bronchitis [7], while in an earlier study, symptom prevalence was similar in workers exposed to $0.22,0.55$ and $1.2 \mathrm{mg} \cdot \mathrm{m}^{-3}$ of respirable dust [24]. The median exposure level of $1.08 \mathrm{mg} \cdot \mathrm{m}^{-3}$ of thoracic dust in the present study indicates lower respirable dust levels [15], probably similar to the latter Taiwan study [24].

Associations between FEV1 and exposure were stronger than with FVC, both using job types and JEM values. These results support the hypothesis that inhalation of cement dust may lead to obstructive lung changes, which is in agreement with some studies where exposure was measured $[6-8,22,23]$ but not with all $[10,12,13,24,25]$. The $270 \mathrm{~mL}$ lower FEV1 estimated for the highest exposure category of the present study compares to the reduction found by YANG et al. [7], although their mean exposure of $3.6 \mathrm{mg} \cdot \mathrm{m}^{-3}$ of respirable dust was probably higher than in our study. Also, using job titles for exposure, other studies found reduced lung function related to cement production [9, 26, 27].

In contrast, the prevalence of airflow limitation was not significantly increased in the exposed workers, except among foremen. A possible interpretation is that serious airflow limitation is rare at the exposure levels in the present study. In a Danish study with a median exposure of $3.3 \mathrm{mg} \cdot \mathrm{m}^{-3}$ of total dust, airflow limitation was associated with cement production work only after 30 yrs of employment [11].

The findings of reduced dynamic lung volumes and increased prevalence of airway symptoms in cement dust-exposed workers are further supported by an in vitro study with rat alveolar macrophages challenged with cement dusts; pro-inflammatory changes and tumour necrosis factor- $\alpha$ activation were significantly associated with the calcium oxide content of the dust [28].

\section{Design aspects}

The prevalence of COPD may be overestimated using the FEV1/FVC $<0.7$ criterion, particularly at older ages [29]. Using the LLN to define COPD allows for the age-dependent decline of the dynamic lung volumes. In a sensitivity analysis, we excluded participants with an age of $\geqslant 45$ yrs and found that the OR of airflow limitation in the two highest exposure quartiles was reduced by half, but still statistically significant. Otherwise, sensitivity analysis in restricted age intervals and countries demonstrated stable associations across strata of age and countries. We also excluded participants reporting doctordiagnosed asthma to improve comparability to COPD studies that included reversibility testing [30], although some of the excluded participants would not obtain normal lung function after bronchodilator use and still meet the COPD criteria. Misclassification of airflow limitation in the present study would probably dilute the effect estimate if independent of exposure status [31].

Using a cross-sectional design, we cannot control the selection into or out of the population, which may result in biased estimates [31]. However, selection effects will be reduced in the future longitudinal analysis. The validity of spirograms was ensured, but since a non-valid spirometry is possibly related to outcomes [32], we chose not to require the most stringent of 
published criteria. The chemical composition of the dust could not be evaluated in this study. This may lead to a misclassification of exposure regarding the inflammatory components of the dust, thus leading to a dilution of exposure-outcome associations assuming non-differential misclassification [31].

Unmeasured confounders, as well as information bias on, for instance, smoking habits, may result in either attenuated or positively biased associations [31].

\section{Exposure}

As the main health outcome in this study is the decline of FEV1 conditioned on dust exposure, particles that deposit in the bronchial tree represent the exposure of interest. Therefore, the thoracic fraction of the workplace aerosol was considered the more relevant. To our knowledge, the present study is the first epidemiological study to estimate exposure to the thoracic fraction of workplace aerosol. It is surprising that this has not been done before because the thoracic fraction estimates the dust entering the lung more accurately than either the total or respirable dust fractions, and the criteria for health relevant particle size fractions were agreed upon in 1993 [16], after the initial suggestion of its criteria by the ACGIH (American Conference of Governmental Industrial Hygienists) in 1968 [15]. A further strength of this study is that we used administrative personnel as well as blue-collar workers with low exposure levels as references, and both strategies resulted in similar associations.

In order to minimise confounding from exposure to crystalline silica, quarry workers were excluded. Crystalline silica may also be found in the raw materials and in trace amounts in the final product. However, measurements indicate that exposure levels to crystalline silica in the jobs types included in this study could occur, but the levels are typically below the current occupational exposure limit (S. Gardi, Italcementi Group, Bergamo, Italy; personal communication).

We used the median exposure levels of job groups as exposure estimates to minimise the influence of outliers. However, the arithmetric mean exposure levels are probably higher. The levels of exposure varied substantially between plants, although all plants used a similar dry production process except the Estonian plant, which used a wet process. Different dust control measures, such as ventilation and filter technology, may partly explain such exposure differences (S. Gardi; personal communication).

The differential use of personal respiratory protection with more prevalent use in the higher exposure groups is considered to potentially dilute the associations between exposure and outcomes in this study; however, confounding was only found regarding FVC. In the analyses using job types for exposure, no confounding by use of personal respiratory protection was demonstrated, probably due to collinearity of variables.

\section{Conclusions and interpretations}

This cross-sectional study demonstrates increased prevalence of airway symptoms and reduction of dynamic lung volumes in production-related jobs compared with administrative jobs, as well as in cement production workers exposed to a median of $\geqslant 0.5 \mathrm{mg} \cdot \mathrm{m}^{-3}$ of thoracic dust compared with workers exposed to levels below this. We demonstrated an exposure-response relationship between exposure and reduced FEV1. The results support the hypothesis that dust exposure in the cement production industry may lead to obstructive lung function changes and airway symptoms.

Interpretation of the study should be performed with caution, since we have no control with selection of employees into and out of the population. This study continues as a prospective study measuring the individual changes in lung function and symptom occurrence.

\section{SUPPORT STATEMENT}

The European Cement Association, CEMBUREAU, provided funding for this study.

\section{STATEMENT OF INTEREST}

A statement of interest for the present study can be found at www.erj. ersjournals.com/site/misc/statements.xhtml

\section{ACKNOWLEDGEMENTS}

We would like to acknowledge I. Claes, A. Tien, S. Gardi and T.R Thomassen (CEMBUREAU, Brussels, Belgium) for launching and organising this study. R. Abderhalden (NIN, Thun, Switzerland) and the group of A. Bergamaschi (G. Somma, A. Pietroiusti, M. Grana, L. Coppeta; University of Rome Tor Vergata, Rome, Italy) are thanked for their scientific cooperation in designing the study and collecting data. Thanks are due to S. Sardan (CEIS, Istanbul, Turkey), S. Gardi (Italcementi, Bergamo, Italy), B. Gumauskas (Cementa, Slite, Sweden), M. Martinez Fidalgo and J. Madera (INS, Alcudia, Spain), T.R. Thomassen (Heidelbergcement/Norcem, Brevik, Norway), P. Toom (Kunda Nordic Tsement, Kunda, Estonia), L. Anastasakis (Titan, Thessaloniki, Greece), and A. Streuli and R. Abderhalden (Jura Cement Fabriken, Wildegg, Switzerland) for their contributions as national coordinators, helping with the organisation, motivation, translation, information and practical solutions leading to the collection of the research data. We also thank T. Nilsen and O. Synnes for technical assistance and K. Corbett for linguistic assistance (NIOH, Oslo, Norway).

\section{REFERENCES}

1 Ahmadi H, Durrant CAT, Sarraf KM, et al. Chemical burns: a review. Curr Anaesth Crit Care 2008; 19: 282-286.

2 Health and Safety Executive. Portland Cement Dust - Hazard Assessment Document EH75/7. Watch committee. Merseyside, Health and Safety Executive, 2004.

3 Bazas T. Effects of occupational exposure to dust on the respiratory system of cement workers. J Soc Occup Med 1980; 30: 31-36.

4 Fell AK, Sikkeland LI, Svendsen MV, et al. Airway inflammation in cement production workers. Occup Environ Med 2010; 67: 395-400.

5 Meo SA. Health hazards of cement dust. Saudi Med J 2004; 25: 1153-1159.

6 Mwaiselage J, Bratveit M, Moen B, et al. Cement dust exposure and ventilatory function impairment: an exposure-response study. J Occup Environ Med 2004; 46: 658-667.

7 Yang CY, Huang CC, Chiu HF, et al. Effects of occupational dust exposure on the respiratory health of Portland cement workers. J Toxicol Environ Health 1996; 49: 581-588.

8 Noor H, Yap CL, Zolkepli O, et al. Effect of exposure to dust on lung function of cement factory workers. Med J Malaysia 2000; 55: $51-57$.

9 Al-Neaimi YI, Gomes J, Lloyd OL. Respiratory illnesses and ventilatory function among workers at a cement factory in a rapidly developing country. Occup Med (Lond) 2001; 51: 367-373.

10 Abrons HL, Petersen MR, Sanderson WT, et al. Symptoms, ventilatory function, and environmental exposures in Portland cement workers. Br J Ind Med 1988; 45: 368-375. 
11 Vestbo J, Rasmussen FV. Long-term exposure to cement dust and later hospitalization due to respiratory disease. Int Arch Occup Environ Health 1990; 62: 217-220.

12 Catenacci G, Tringali S, Brunetti G, et al. [Decrement of respiratory function indices in a case series of workers exposed to cement dust: a longitudinal study]. G Ital Med Lav 1988; 10: 123-129.

13 Fell AK, Thomassen TR, Kristensen P, et al. Respiratory symptoms and ventilatory function in workers exposed to portland cement dust. J Occup Environ Med 2003; 45: 1008-1014.

14 AbuDhaise BA, Rabi AZ, al Zwairy MA, et al. Pulmonary manifestations in cement workers in Jordan. Int J Occup Med Environ Health 1997; 10: 417-428.

15 Vincent JH. Particle size-selective criteria for fine aerosol fractions. In: Aerosol Sampling. Science, Standards, Instrumentation, and Applications. John Wiley \& Sons Ltd, Chichester, 2007; pp. 255-287.

16 Comité Européen de Normalisation. Workplace Atmospheres. Size Fractions Definition Procedures for Measurement of Airborne Particles (EN481). Brussels, CEN, 1993.

17 Miller MR, Hankinson J, Brusasco V, et al. Standardisation of spirometry. Eur Respir J 2005; 26: 319-338.

18 Quanjer PH, Tammeling GJ, Cotes JE, et al. Lung volumes and forced ventilatory flows. Report Working Party Standardization of Lung Function Tests, European Community for Steel and Coal. Official Statement of the European Respiratory Society. Eur Respir J 1993; 6: S5-S40.

19 Toren K, Brisman J, Jarvholm B. Asthma and asthma-like symptoms in adults assessed by questionnaires. A literature review. Chest 1993; 104: 600-608.

20 Vestbo J, Knudsen KM, Rasmussen FV. The effect of smoking and occupation on changes in respiratory symptoms in middle-aged Danish men. Eur Respir J 1990; 3: 880-885.

21 Mwaiselage J, Bratveit M, Moen B, et al. Respiratory symptoms and chronic obstructive pulmonary disease among cement factory workers. Scand J Work Environ Health 2005; 31: 316-323.
22 Neghab M, Choobineh A. Work-related respiratory symptoms and ventilatory disorders among employees of a cement industry in Shiraz, Iran. J Occup Health 2007; 49: 273-278.

23 Mirzaee R, Kebriaei A, Hashemi SR, et al. Effects of exposure to Portland cement dust on lung function in Portland cement factory workers in Khash, Iran. Iran J Environ Health Sci Eng 2008; 5: 201-206.

24 Yang CY, Huang CC, Chang IC, et al. Pulmonary function and respiratory symptoms of Portland cement workers in southern Taiwan. Gaoxiong Yi Xue Ke Xue Za Zhi 1993; 9: 186-192.

25 Rasmussen FV, Borchsenius L, Holstein B, et al. Lung function and long-term exposure to cement dust. Scand J Respir Dis 1977; 58: 252-264.

26 Saric M, Kalacic I, Holetic A. Follow-up of ventilatory lung function in a group of cement workers. Br J Ind Med 1976; 33: 18-24.

27 Meo SA, Azeem MA, Ghori MG, et al. Lung function and surface electromyography of intercostal muscles in cement mill workers. Int J Occup Med Environ Health 2002; 15: 279-287.

28 van Berlo D, Haberzettl P, Gerloff $\mathrm{K}$, et al. Investigation of the cytotoxic and proinflammatory effects of cement dusts in rat alveolar macrophages. Chem Res Toxicol 2009; 22: 1548-1558.

29 Swanney MP, Ruppel G, Enright PL, et al. Using the lower limit of normal for the FEV1/FVC ratio reduces the misclassification of airway obstruction. Thorax 2008; 63: 1046-1051.

30 Pauwels RA, Buist AS, Calverley PM, et al. Global strategy for the diagnosis, management, and prevention of chronic obstructive pulmonary disease. NHLBI/WHO Global Initiative for Chronic Obstructive Lung Disease (GOLD) Workshop summary. Am J Respir Crit Care Med 2001; 163: 1256-1276.

31 Rothman KJ, Greenland S. Precision and validity in epidemiologic studies. In: Rothmann KJ, Greenland S, eds. Modern Epidemiology. 2nd Edn. Philadelphia, Lippincott-Raven, 1999; pp. 115-134.

32 Becklake MR. Epidemiology of spirometric test failure. $\mathrm{Br} J$ Ind Med 1990; 47: 73-74. 